J. Lake Sci.(湖泊科学), $2018, \mathbf{3 0}(4)$ : 865-880

DOI 10. 18307/2018. 0401

(c) 2018 by Journal of Lake Sciences

\title{
长江上游水库改变干流磷通量、效应与修复对策
}

\author{
周建军 ${ }^{1}$, 张 曼 $^{1}$, 李 哲 ${ }^{2}$ \\ ( 1 : 清华大学水利系, 北京 100084) \\ (2: 中国科学院重庆绿色智能技术研究院,重庆 400714)
}

\begin{abstract}
摘 要: 磷主要随河川径流循环, 是水域重要营养或污染物质, 是长江及河口浮游生物限制因子. 在自然与人类活动作用 下, 磷循环规律及变化对水生态环境具有重要作用. 本文根据实测资料、理论和模型系统分析了长江磷自然循环属性、水 库作用及可能的环境影响. 长江磷以颗粒态为主, 与泥沙关系密切, 受水库影响大量沉积; 颗粒磷的潜在生物有效磷 (BAP) 较高, 总量超过人类排放; 自然背景下磷与淡水系统关系较小, 到河口及周边海域释放 BAP 是这里生态系统关键 的营养资源; 水库拦截使在底泥沉积并在缺氧环境释放的 BAP 成为河流上游潜在污染源. 水库拦沙也破坏了下游河流泥 沙的磷缓冲机制, 增加环境脆弱性, 降低污染承受能力, 抬高水库下泄背景溶解磷浓度和河口碳、氮的相对程度, 增加干 流最下游大型水库污染和水华风险. 另一方面, 实测资料对比研究表明, 我国河流地表水环境监测规范中的磷分析方法 存在问题,采用“澄清样”方法使磷大量漏测, 上下游、河湖库及汛枯期间磷通量监测口径不同、标准不一, 很难适应流域 一体化管理要求; 依此监测的评估也会严重低估水库作用,忽视其拦磷和抬高背景溶解磷等机制, 误导污染源解析, 影响 环境管理与决策. 流域水库改变泥沙、磷及循环规律是当前长江干流环境条件的实质性改变, 是长江保护生态面临的主 要问题和修复重点之一,建议在大型水库持续挖泥用以功能性修复河流物质通量和消除上游潜在污染内源.
\end{abstract}

关键词: 磷;泥沙; 水库;生态环境;长江保护

\section{Dams altered Yangtze River phosphorus and restoration countermeasures}

ZHOU Jianjun ${ }^{1}$, ZHANG Man ${ }^{1} \&$ LI Zhe ${ }^{2}$

(1: Department of Hydraulic Engineering, Tsinghua University, Beijing 100084, P.R.China)

(2: Chongqing Institute of Green and Intelligent Technology, Chinese Academy of Sciences, Chongqing 400714, P.R.China)

\begin{abstract}
Phosphorus ( P ), as a limiting and vital macronutrient in global freshwaters, circulates mainly with sediment through rivers. In this paper, we analyzed and summarized the regime of $\mathrm{P}$ and its variations that induced by dams burgeoning in the upper Yangtze River basins in recent decades. We revealed that more than $91 \%$ of the P flux is in particulate form, among which the potential dissolvable bio-active P ( BAP) can exceed the total load that discharged from the riparian basins. The P is closely correlated with sediment and we estimated that reservoirs have by more than 3 quarters of it sequestrated. Previously, the BAP was mostly absorbed by sediment and flushed by floods to the estuary, where it supported a flourishing saline bio-ecosystem at the same time, with minor residuals in the lowland freshwaters. However, this nature endowed regime was upset by the sequestration of reservoirs that reallocated reversely the background $\mathrm{P}$ as inner pollution for the freshwater corridors and snatched the inherent nutrient for ecosystem of the estuary. Moreover, the resultant clear-stream lost its buffering effect that sediment regulates $\mathrm{P}$ and the lowland freshwater becomes more vulnerable with lowered environmental capacity. Accounting for the actual eutrophic status, the pool elevated dissolvable $\mathrm{P}$ level may also add potential risks in stimulating harmful algal blooms and hypoxia to the Three Gorges Reservoir and others. On another hand, in order to keep a basin wide consistent monitoring and criterions in $\mathrm{P}$ control from water to water and we can evaluate the harmful effect of dams more objectively, we recommend urgently to correct the present $\mathrm{P}$ analysis regulation, which requires $\mathrm{P}$ extraction from water samples after $30 \mathrm{~min}$ settling, that can lose a significant amount of P. Finally, we proposed to restore the downstream biogenic-substance and eliminate the in-pool accumulating $\mathrm{P}$ contamination through successive slurry dredging from reaches in front of the dams.
\end{abstract}

* 国家重点研发计划 (2016YFE0133700) 和国家自然科学基金项目 (51509137) 联合资助. 2017-11-01 收稿; 201712-06 收修改稿. 周建军(1960 ), 男,博士, 教授;E-mail:zhoujj@ tsinghua.edu.cn. 
Keywords: Phosphorus; sediment; reservoirs; eco-environment; Yangtze River protection

过去 20 余年, 长江流域水利水电工程建设和经济社会发展取得了巨大成绩, 但资源开发和污染增加的 同时也加大了流域生态环境压力, 河湖出现了不容忽视的趋势性改变. 上游大量建坝和水库调控显著改变 了河川径流节律、泥沙、温热条件和水域环境面貌, 对生态环境和环境容量产生重要影响 ${ }^{[1]}$. 国家把河流保 护作为长江经济带建设基本要求,生态环境修复作为压倒性任务. 在此要求下, 正确把握环境容量保护与污 染控制的关系对协调发展与保护意义重大, 正确认识各种人类活动对生态环境变化的作用与影响可以帮助 我们抓住保护与修复的主要问题和矛盾和减少失误.

近年来, 在长江污染增加的同时, 河川径流、泥沙和水及区域温热条件等都在变化以及对环境产生影响. 与历史相比, 2003 年三峡蓄水以来宜昌断面年径流量减少、径流干旱机率增加. 特别是伏秋季中下游流量迅 速减少、水位剧烈降低、湖泊与河流洲滩提前干枯, 河湖生态和环境条件发生了很大变化. 三峡水库滞热效 应使 2009-2014 年宜昌实测春末水温降低 $4.4^{\circ} \mathrm{C}$, 冬季升高 $4.1^{\circ} \mathrm{C}$ 、水温超过气温 $10 \sim 13^{\circ} \mathrm{C}$ 、水库增加热通量 散发 2.5 亿 $\mathrm{kW}$. 上游干热河谷大量水库蓄水后, 还将进一步增加吸收短波辐射, 水库聚热效应对相对阴冷的 三峡水库水质和蒸发将带来更大影响. 更重要的是水库彻底改变了长江中下游泥沙, 2004-2016 年与长系 列 ( $1953-1990$ 年) 平均值比较, 宜昌下泄输沙量减少了 $92.6 \%$; 2013- 2016 年上游水库拦沙后又使三峡人 库输沙量比长系列减少 $90.6 \%$, 宜昌输沙量减少至天然的 $1.4 \%$. 水库彻底改变了长江泥沙条件, 中下游已经 变成了 “清水河流”. 由于上游巨大的拦沙库容, “清水河流” 至少维持 200 300 年. 对于天然的冲积型平原 河流, 这是本质性改变, 泥沙条件改变对长江河流面貌将造成多方面巨大影响 ${ }^{[2]}$, 其中生态环境条件改变是 重要和最现实的影响. 但是, 关于水库泥沙淤积的生态环境效应, 比如对磷和其他污染物循环的影响, 迄今 在认识上还存在很大不足, 很多关键问题在三峡等工程论证中没有得到应有的重视甚至被忽略. 比如, 三峡 工程论证中, 泥沙研究认为大约 $8 \mu \mathrm{m}$ 以下的细泥沙不会在水库淤积, 长江中下游最少可以维持不低于 1.8 亿 $\mathrm{t}$ 的细泥沙通量 ${ }^{[3]}$, 因此泥沙研究没有考虑相关的生态环境问题 ${ }^{[4]}$. 而现实是 $8 \mu \mathrm{m}$ 以下泥沙淤积比例达 $74 \%$ 、宜昌断面总量减少 $92 \%$. 由于泥沙与磷关系密切, 磷是河流生态的重要限制因子 ${ }^{[5]}$, 埃及阿斯旺高坝 1965 年拦沙致使下游地中海河口鱼量减少 $86 \%{ }^{[6]}$, 原因是尼罗河泥沙含磷密度达 $1.46 \mathrm{mg} / \mathrm{g}(\text { 表 } 1)^{[7]}$, 泥沙 和磷减少使坝下生境退化 ${ }^{[6]}$. 三峡水库蓄水以来, 尽管下泄水质指标长期处于 II 类 ( 优于以前)、但在长江渔 获量没有增加的情况下, 鱼反而剧烈减少. 我们不能简单将其只怪罪于过度捕捞和污染, 泥沙和磷改变也是 影响淡水和河口周边海域生境的重要环境要素. 而三峡工程论证和后三峡上游大量水库规划都忽略了水库 淤积细泥沙在这方面的环境作用. 关于长江磷循环规律、磷与泥沙关系和水库作用, 国内外学者高度重视并 进行了大量研究, 得到了很多重要认识 ${ }^{[8-16]}$, 作者对此有系统的综述 ${ }^{[17-18]}$. 目前, 对长江上游水库群拦沙拦 磷的综合作用结合这些工程的运行情况进行系统总结, 以服务于当前的长江生态环境修复.

近年来, 作者 ${ }^{[17-18]}$ 根据实测泥沙和磷等资料, 研究了长江磷与泥沙的关系和水库作用、水库改变磷等物 质循环与转换规律、环境作用和深远影响. 本文综合讨论了长江河流磷与泥沙的关系, 干流磷通量及其循环 规律的宏观变化和发展趋势, 同时分析了流域水库泥沙和磷淤积对干流等水域生态环境可能产生的影响, 在认识基础上提出了修复长江磷等河流物质通量的建议措施. 这些讨论和对策建议对认识长江生态环境主 要问题和研究长江生态环境修复重点应该具有一定参考作用.

\section{1 数据和方法}

本研究所有水文大数据依据三峡水库上下游主要控制断面 ( 朱沱、寸滩、清溪场、宜昌、北碚和武隆等, 图 1) 实测的长系列 (1953-2016 年) 逐日流量、泥沙浓度、水位和水温,逐月泥沙级配以及 2005-2012 年每 月 1 次在库区多断面同步的氮、磷等污染物监测数据. 数据来自长江水利委员会水文局和长江上游水文局.

氮、磷与不同级配泥沙之间的关系分析主要依据了长江上游水文局 2002 年 9 月至 2003 年 5 月和 2004 年 5-9 月三峡蓄水前后两套原型观测数据 ${ }^{[17]}$, 磷级配分析总共进行了 34 次. 观测在朱沱、北碚、寸滩、武 隆、清溪场、万县和奉节等断面同步采样, 含沙水样按水利部河流泥沙规范在断面左中右三垂线和每垂线上 中下三点取样和分析. 泥沙级配测量按移液法; 磷级配采用孔径为 $200 、 63 、 20 、 8$ 和 $0.45 \mu \mathrm{m}$ 膜分别过滤后, 


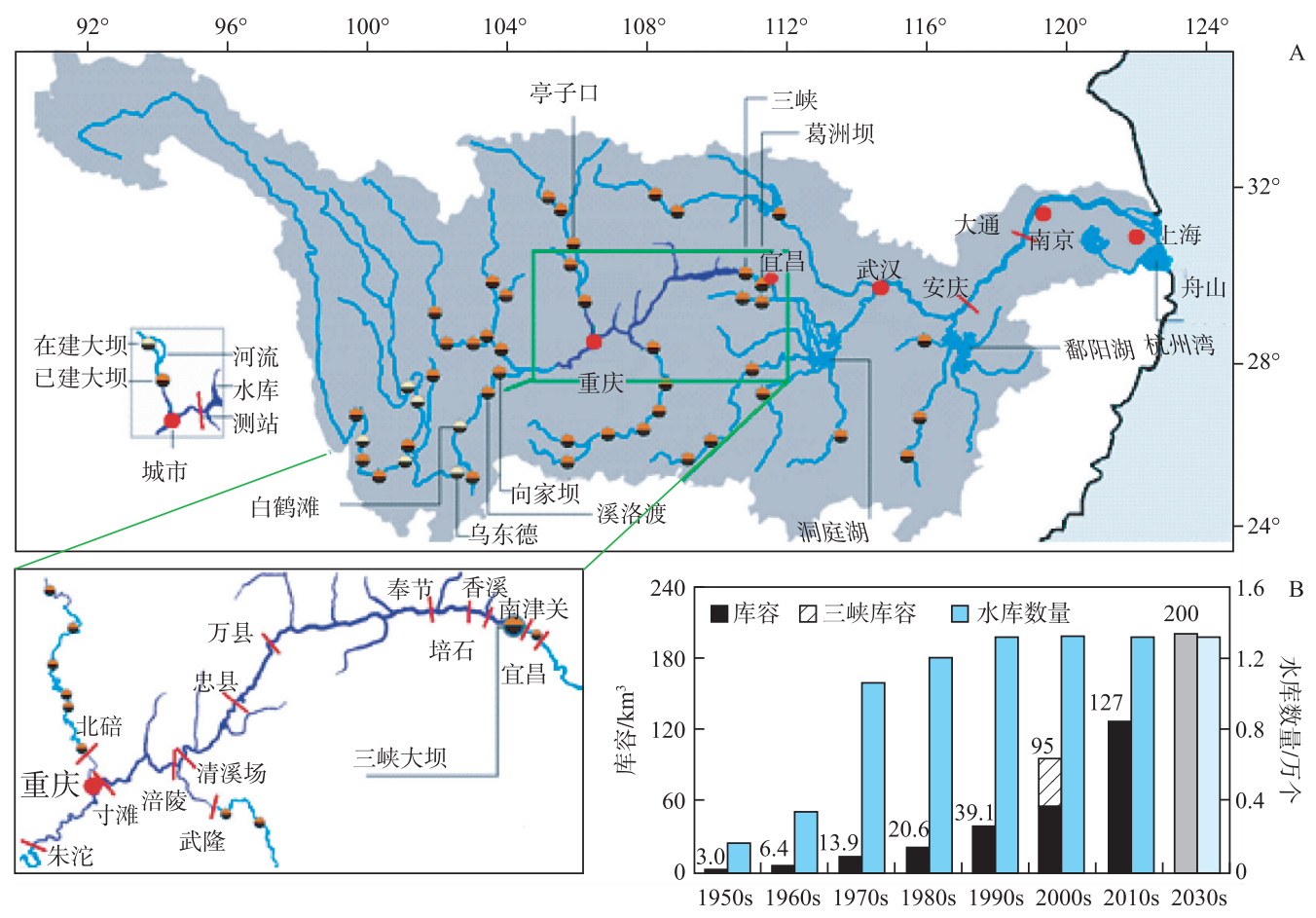

图 1 长江流域主要大坝、相关观测站和重要位置 $(A)$ 、上游水库数量和库容 (2030s 是规划资料) (B)

Fig. 1 Sketch of the Yangtze valley with large dams, gauging stations and important positions(A) and the developing diagram of the numbers and capacity of dams in the upper basin(B)

按钿酸铵分光光度法测量相应水沙总磷 ( TP), 其中 $0.45 \mu \mathrm{m}$ 膜下水样含磷量为溶解磷浓度. 这样得到的颗 粒磷 $(\mathrm{PP})$ 和总磷比环境保护部监测规范按澄清样分析的 TP 和总氮 $(\mathrm{TN})$ 数据更完整和符合实际. 本文采 用的溶解氧、气温和水温等其他数据 (除特别指出外) 都是实测资料. 同时, 还采用了大量公开发表的原型观 测数据 ${ }^{[11-12,15,19]}$.

泥沙和磷通量概算等主要依据实测资料和统计模型 ${ }^{[17-18]}$,包括泥沙通量模型(公式(1) (2)) ( 模型 1)、 浓度模型( 公式(3) (5)) (模型 2) 和面积浓度模型 (公式(6) (9)) (模型 3)：

$$
\begin{gathered}
L_{\mathrm{TP}}=1.05 Q_{\mathrm{s}}^{0.748} \quad\left(R^{2}=0.9277\right) \\
L_{\mathrm{PP}}=0.757 Q_{\mathrm{s}}^{0.816}\left(R^{2}=0.940\right) \\
P P=0.408 s^{0.68} \\
T P=\frac{0.408 s^{0.68}(1+62.5 s)^{0.67}}{(1+62.5 s)^{0.67}-1} \\
D P=\frac{0.408 s^{0.68}}{(1+62.5 s)^{0.67}-1} \\
\lg D_{\mathrm{a}}=0.103 \lg ^{2} C_{\mathrm{a}}-0.086 \lg C_{\mathrm{a}}+0.065 \quad\left(R^{2}=0.61\right) \\
D P=\frac{T P \quad\left(1+2.85 \sqrt{C_{\mathrm{a}}}\right)^{3}}{\left(1+R^{2}=0.715\right)} \\
T P=\frac{P P=C_{\mathrm{a}} \cdot D_{\mathrm{a}}}{1-\left(1+2.85 \sqrt{C_{\mathrm{a}}}\right)^{-3}}
\end{gathered}
$$

式中, $T P 、 P P 、 D P$ 分别为总磷、颗粒磷和溶解磷浓度 $(\mathrm{mg} / \mathrm{L}), L_{\mathrm{TP}}$ 和 $L_{\mathrm{PP}}$ 分别为相应通量 $(\mathrm{kg} / \mathrm{s}), Q_{\mathrm{s}}$ 为输沙率 $(\mathrm{t} / \mathrm{s}), s$ 为泥沙浓度 $(\mathrm{g} / \mathrm{L}), C_{\mathrm{a}}\left(=6 \times 10^{-3} s / \gamma_{\mathrm{s}} \Sigma_{p_{i}} / d_{i}\right)$ 为泥沙面积浓度 $\left(\mathrm{m}^{2} / \mathrm{L}\right), D_{\mathrm{a}}$ 为磷面积浓度 
$\left(\mathrm{mg} / \mathrm{m}^{2}\right), \gamma_{\mathrm{s}}>p_{i}$ 和 $d_{i}$ 分别为泥沙比重 $\left(\mathrm{kg} / \mathrm{m}^{3}\right)$ 、分组比例 $(\%)$ 和粒径 $(\mathrm{mm})$.

三峡水库泥沙淤积计算采用一维数学模型 ${ }^{[20]}$, 按不平衡输沙模式计算不均匀泥沙在水库中分选淤积过 程. 模型曾用实验室、原型和三峡水库 2003-2005 年实测资料检验, 在三峡水库泥沙调度和管理研究中有 较多应用 ${ }^{[20-21]}$. 不均匀沙按界限粒径 $<1.9 、 1.9 \sim 6.0 、 6.0 \sim 16.4 、 16.4 \sim 43.5 、 43.5 \sim 87.0 、 87.0 \sim 124.0 、 124.0 \sim$ 368.0 和 $>368.0 \mu \mathrm{m}$ 共 8 组, 从朱沱至坝前用 432 个断面离散 (含嘉陵江和乌江 2 个支流), 采用 $1961-1970$ 和 1993-2002 年两个实测水沙系列, 按三峡设计运行方式 ${ }^{[4]}$ 循环计算 100 年. 磷输运和淤积计算根据上述 模型 3 与泥沙模型同步计算 (假设磷在水沙之间吸附平衡, 无需边界条件). 值得指出的是, 因三峡实际人库 泥沙与上述研究系列相差很大,模型计算结果仅用于分析水库对磷的作用.

\section{2 河流磷与泥沙的关系}

磷是自然水域主要的大营养或污染物之一. 在全球循环中通过大气沉降磷 300 万 400 万 $\mathrm{t}^{[22]}$ 或 350 万 $\mathrm{t}^{[23]}$, 而通过风化、侵蚀和径流输送入海 TP 2500 3000 万 $\mathrm{t}$, 其中 PP 平均占 $89 \%{ }^{[22]}$. 河流是磷输送的主要通道. 磷与泥沙之间有很强亲和力, 除自然磷外, 其他磷离子也极易与泥沙结合成为 $\mathrm{PP}^{[19]}$, 因此河流磷主要以泥 沙为载体. 世界多数大河磷通量中 PP 超过 $80 \%$ 90\% (表 1). 除个别少沙小河流外,亚马逊河、长江和黄河 等 PP/TP 远大于 $90 \%$, 多数河流泥沙含磷密度超过 $0.5 \mathrm{mg} / \mathrm{g}$. 世界最大的亚马逊河和刚果河泥沙磷密度超 过 $1.5 \mathrm{mg} / \mathrm{g}^{[30]}$, 涺公河更高达 $4.0 \mathrm{mg} / \mathrm{g}^{[31]}$, 我国长江、黄河和珠江泥沙磷密度分别为 $0.5 、 0.6$ 和 $0.3 \mathrm{mg} / \mathrm{g}^{[32]}$ (表 1). 全球磷循环主要以泥沙为载体、河流为通道向海洋汇集, 河流泥沙运动在很大程度上决定了磷的去 向和循环路径.

图 2 是根据三峡水库蓄水前后原型观测得到的长江磷、氮与泥沙相关关系. 可见磷与泥沙高度相关, 河 流输送 PP 和 TP 主要由输沙量决定. 考虑到磷的颗粒亲和特性 ${ }^{[19]}$, 这一相关关系具有物理基础. 图 $2 \mathrm{~b}$ 表明 氮与泥沙几乎没有关系. 因此, 水库拦沙的同时会将磷扣押在底泥中而淤积对氮作用不大. 水库拦磷对磷和 氮具有分选作用. 因此, 水库淤积会影响下游水域的营养结构 (氮磷比, N/P). 另一方面, 根据实测磷级配分 布资料 ${ }^{[18]}$ ( 考虑到过滤膜对泥沙具有的孔口效应——细泥沙被大于孔口的粗沙堵塞,进一步通过对比实验 对过 $20 \mu \mathrm{m}$ 以下孔口的磷比例进行了修正) 显示, 磷在单位泥沙面积上吸附密度和溶解磷比例 ( DP/TP) 都 与水中泥沙面积浓度呈反比关系 (公式 (6) 和 (7)), 泥沙面积浓度越大, 吸附磷的密度和溶解磷的比例都越 小 (图 2c,d). 证明在长江泥沙浓度较大或颗粒较细时, 单位泥沙表面积含磷还很低, 细泥沙仍比较干净, 吸 附能力大, 在河流或淡水系统中还有很大环境潜力.

泥沙磷密度和 BAP/PP 比例对于长江泥沙及磷的生态环境作用很大. 一般认为颗粒磷中弱吸附态磷、 有机磷和铁结合态磷是 $\mathrm{BAP}^{[15]}$. 大量研究 ${ }^{[8,32,49]}$ 显示, 长江泥沙颗粒的平均磷密度超过 $0.5 \mathrm{mg} / \mathrm{g}$, 这在全球 河流中是不高的 (表 1). 同时, 全球人海泥沙的平均 BAP/PP 比例是 $25 \% \sim 70 \%{ }^{[50-51]}$, 美国大湖流域支流和 湖区 BAP/PP 比例分别为 $33 \%$ 和 $40 \%$. 根据魏俊风等 ${ }^{[15]}$ 沿江采样分析, 长江上游涪陵至宜昌实测的 BAP/PP 比例 $27.5 \% \sim 50.5 \%$ 、下游安庆和大通比例超过 65\% (表 2). 可见, 试可按 BAP/PP $=0.25 \sim 0.33$ 或单位泥沙 BAP 密度 $0.2 \mathrm{mg} / \mathrm{g}$ 估算宜昌 BAP 通量. 根据后面的 TP 概算结果 (表 3), 天然宜昌 (1961-1990 年) 平均 PP 通量 19 万 22 万 $\mathrm{t}$ 或泥沙通量 5.21 亿 $\mathrm{t}$ 计算, 长江每年进人中下游的潜在生物有效磷通量达到 6 万 7 万或 10 万 t. 2015 年长江三峡库区 ( 培石) 和三峡下游 (南津关) 实测的澄清样总磷通量分别为 6.5 万 ${ }^{[50]}$ 和 4.2 万 $\mathrm{t}^{[53]}$. 即使假设其总磷中 BAP 占绝对多数, 并假设实测总磷都是污染排放所致 ( 实际上背景值还占相当比例), 观 测数据与上述概算比较显示, 长江上游泥沙携带的潜在 BAP 数量超了当前人类活动排放的总磷.

另一方面, 根据模型估算天然长江 TP 91\% 95\% 随泥沙输送, 同时由于 $86 \%$ \% $88 \%$ 的泥沙主要在汛期 (6-10 月) 输送人海 (表 3). 尽管每年长江输送大量的 PP 通量, 但是考虑到泥沙主要在汛期人海 (汛期河 流淡水系统环境容量很大), 汛期高磷通量、高 PP 及高 DP 对内河环境的作用很小, 长江输送 TP 对内陆水 域环境有作用的主体是非汛期 DP. 可以估算, 长江 TP 对淡水系统有环境作用磷的比例只有 $3.2 \% \sim 3.5 \%=$ [ (1-0.91) ×0.36 0.39] (其中 0.36 和 0.39 分别是 1960-1990 和 1991-2002 年非汛期平均 DP 比例). 可 见, 天然情况下长江磷通量对淡水系统环境作用很小. 但是, 这些 PP 进人河口咸水系统后, 因为盐水促进铁 的转移会将与铁结合的磷 (BAP 主体) 等置换出来 ${ }^{[54-55]}$. 上游水库使河口 BAP 供给量大量减少. 
表 1 世界主要河流水、沙和磷通量特征数据

Tab.1 The fluvial fluxes of water, sediment and phosphorus in some largest world rivers

\begin{tabular}{|c|c|c|c|c|c|c|}
\hline 河流 & $\begin{array}{c}\text { 径流量/ } \\
\left(\mathrm{km}^{3} / \mathrm{a}\right)^{[27]}\end{array}$ & $\begin{array}{l}\text { 输沙量/ } \\
(\mathrm{Mt} / \mathrm{a})^{[28]}\end{array}$ & $\begin{array}{c}\mathrm{PO}_{4}^{3}-\mathrm{P} / \\
(\mathrm{mg} / \mathrm{L})^{[29]}\end{array}$ & $\begin{array}{c}\mathrm{DP} / \\
(\mathrm{mg} / \mathrm{L})\end{array}$ & $\begin{array}{l}\mathrm{PP} \text { 密度/ } \\
(\mathrm{mg} / \mathrm{g})^{[29]}\end{array}$ & $\begin{array}{c}\mathrm{PP} / \mathrm{TP} / \\
\%\end{array}$ \\
\hline Amazon & 6500 & 1200 & 0.022 & $0.023^{[30]}$ & 1.65 & 92.3 \\
\hline Congo & 1290 & 65 & 0.024 & & $1.50 \sim 2.10$ & $56.0 \sim 63.4$ \\
\hline Orinoco & 1135 & 150 & $0.0062^{[26]}$ & & 0.55 & 82.4 \\
\hline 长江 & 920 & 478 & $0.0045^{[29]}$ & & $0.50^{[32]}$ & 95.8 \\
\hline Ganges & 690 & 1670 & 0.075 & $0.10^{[31]}$ & 0.50 & 86.6 \\
\hline Brahmaputra ${ }^{[31]}$ & & & & & 0.96 & 75.0 \\
\hline Ganges $^{[31]}$ & & & 0.12 & & 1.36 & 86.0 \\
\hline Mississippi & 658 & 210 & & $0.06^{[33]}$ & $\begin{array}{c}0.156(\mathrm{mg} / \mathrm{L})^{[34]} \\
1.1^{[35]}\end{array}$ & $\begin{array}{c}72.0 \\
70.0^{[36]}\end{array}$ \\
\hline Lena & 530 & 15 & 0.004 & & 0.443 & 56.0 \\
\hline Mekong & 500 & 170 & $0.076^{[31]}$ & & $4.0^{[31]}$ & $98.6^{[31]}$ \\
\hline 珠江 & 302 & 69 & $0.004^{[32]}$ & & $0.3^{[32]}$ & 88.1 \\
\hline Zambezi & 220 & 100 & 0.01 & & 0.99 & 94.7 \\
\hline Indus & 200 & 100 & $0.15^{[26]}$ & & 0.9 & 83.9 \\
\hline Danube & 200 & 67 & $\begin{array}{c}0.035 \\
0.02^{[37]}\end{array}$ & & $\begin{array}{c}0.79 \\
0.776^{[38]}\end{array}$ & $\begin{array}{c}75.2\left(84.0^{[32]}\right) \\
62.0^{[38]}\end{array}$ \\
\hline Yukon $^{[44]}$ & 200 & 88 & & & $0.39 \sim 0.93$ & 94.0 \\
\hline Niger & 190 & 67 & 0.013 & & $1.6 \sim 3.0$ & $64.0 \sim 76.5$ \\
\hline Godavari & 92 & 170 & 0.16 & & 0.83 & $79.0^{[31]}$ \\
\hline Po & 46 & & 0.075 & & 1.40 & 82.3 \\
\hline $\operatorname{Nile}(1965$ 年前) & 43 & $25^{[6]}$ & & $0.198^{[7]}$ & $1.46^{[7]}$ & 81.0 \\
\hline 黄河 & $33.1^{[39]}$ & $839^{[39]}$ & $0.0093^{[32]}$ & & $0.6^{[32]}$ & 99.8 \\
\hline Garonne-Dordogne & 32 & $1.86^{[40]}$ & 0.104 & & 1.3 & 42.1 \\
\hline Neva & 80 & 0.82 & 0.03 & & $0.53 \sim 1.28^{[41]}$ & $37.0 \sim 58.3$ \\
\hline Colorado & 23 & & & & $0.4 \sim 1.3^{[42]}$ & $>95.0^{[43]}$ \\
\hline Salmon $^{[45]}$ & & & & 0.085 & 1.06 & 81.4 \\
\hline Chena $^{[46]}$ & & & & 0.007 & $1.1 \sim 9.6$ & 74.0 \\
\hline Apure ${ }^{[33]}$ & 60 & & & 0.06 & $0.128(\mathrm{mg} / \mathrm{L})$ & 68.1 \\
\hline Severn $^{[47]}$ & 2.6 & 1.7 & & 0.24 & 0.28 & 43.0 \\
\hline Avon $^{[47]}$ & 0.5 & 0.5 & & 0.84 & 0.28 & 26.0 \\
\hline $\operatorname{Exe}^{[47]}$ & 0.5 & 0.2 & & 0.06 & 0.27 & 68.0 \\
\hline $\operatorname{Dart}^{[47]}$ & 0.03 & 0.02 & & 0.067 & 0.26 & 75.0 \\
\hline Marne $^{[48]}$ & & & & & 0.96 & 13.4 \\
\hline
\end{tabular}

数据来源于每列表头文献 (具体标注除外); $\mathrm{PP}$ 通量根据 $\mathrm{PP}$ 密度计算; $\mathrm{TP}=\mathrm{PP}+\mathrm{DP}$; 无 DP 数据的 DP 按 2.5 倍磷酸盐 计算 ${ }^{[26]}$.

表 2 涪陵一大通 2006 年 9-10 月实测 PP 及其潜在 $\mathrm{BAP}^{[15]}$

Tab.2 Measured sediment, PP and BAP along the Yangtze River from Fuling to Datong, Sep.-Oct. 2006 ${ }^{[15]}$

\begin{tabular}{ccccccccc}
\hline & 涪陵 & 忠县 & 万县 & 香溪 & 三峡大坝前 & 宜昌 & 安庆 & 大通 \\
\hline 流量 $/\left(\mathrm{m}^{3} / \mathrm{s}\right)$ & 11700 & 11550 & 11400 & 9009 & 8320 & 8320 & 12100 & 16500 \\
泥沙浓度 $/\left(\mathrm{kg} / \mathrm{m}^{3}\right)$ & 1.012 & 0.276 & 0.152 & 0.020 & 0.019 & 0.016 & 0.063 & 0.058 \\
$\mathrm{PP} /(\mathrm{mg} / \mathrm{g})$ & 0.816 & 0.829 & 0.771 & 0.910 & 1.054 & 1.052 & 0.763 & 0.761 \\
$\mathrm{BAP} /(\mathrm{mg} / \mathrm{g})$ & 0.271 & 0.231 & 0.212 & 0.418 & 0.463 & 0.531 & 0.522 & 0.502 \\
\hline
\end{tabular}




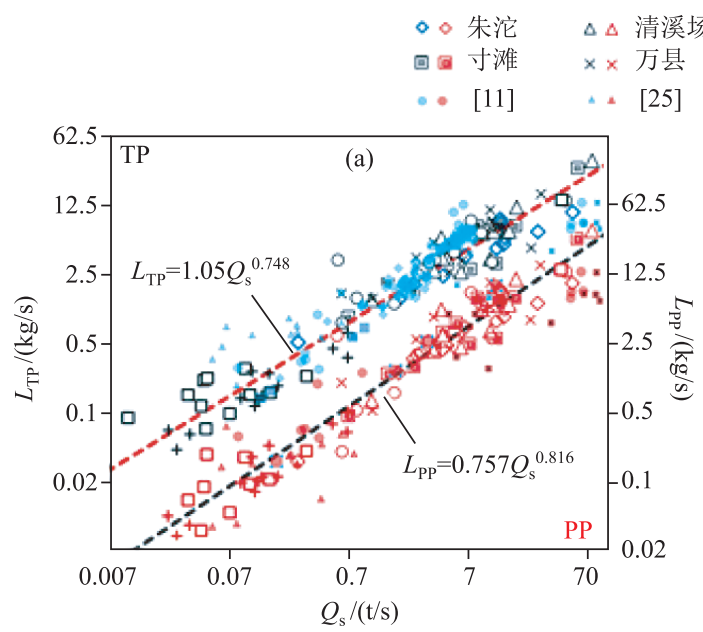

$$
\begin{aligned}
& \text { ○奉节 ++ 武隆 } \\
& \text { 口北碚 }=\text { 曰 [15] } \\
& \therefore \text { [14] }
\end{aligned}
$$
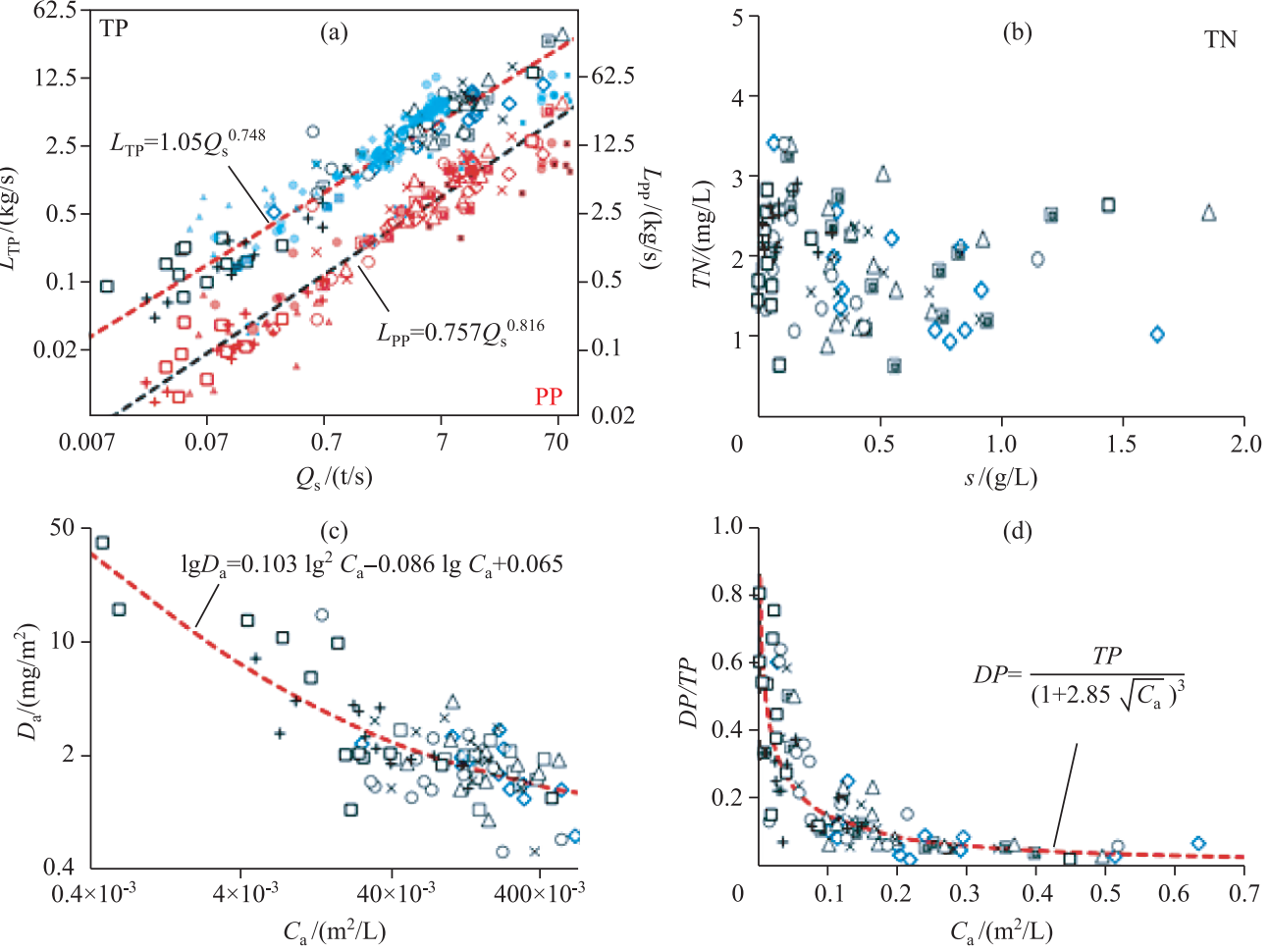

图 2 三峡段实测 TP 和 PP 与输沙率 (a)、TN 与泥沙浓度 (b)、磷面积密度与泥沙面积浓度 (c) 和 溶解磷比例与泥沙面积浓度 (d) 的关系 (TP、PP 与 $Q \mathrm{~s}$ 相关系数分别是 $R^{2}=0.928$ 和 $0.940, \mathrm{TN}$ 与 $s$ 之间 $R^{2}=0.0433$. 其中, 文献数据没有用于公式回归,只用于公式检验)

Fig.2 The measured data and relationships of TP and PP (a), TN (b), areal density (c) and the ratio of DP/TP (d) against sediment measurements

\section{3 长江干流磷通量宏观变化}

长江磷与泥沙关系密切, 泥沙改变是磷通量变化的根本原因. 图 3 是 1950-2016 年长江宜昌断面水沙 及变化情况. 1990 年前 40 年间长江上游基本处于天然状况, 水沙平稳, 平均径流量和输沙量分别是 4390 亿 $\mathrm{m}^{3} / \mathrm{a}$ 和 5.21 亿 t/a. 2003 年后, 长江径流量有一定程度减少而泥沙减少剧烈. $2003-2016$ 年平均输沙量只 有 3810 万 $\mathrm{t} / \mathrm{a}, 2014-2016$ 年不足 1000 万 $\mathrm{t} / \mathrm{a}$, 比 1950-1990 年减少 $98.6 \%$. 同时, 与磷等污染物输移和生 态环境关系密切的 $8 \mu \mathrm{m}$ 以下粒径细泥沙也显著减少, 2009-2016 年这种细沙通量比 1990 年前减少 $94.8 \%$. 尽管同期长江中下游发生了大量冲刷 ${ }^{[54]}$, 但 2003-2012 年长江出海输沙量仍然减少 70\% 以上. 随着清水冲 刷过程发展, 出海泥沙还会大幅度减少.

表 3 是根据 3 个模型概算 1961-1990、1991-2002 和 2003-2012 年 3 时段宜昌断面年平均磷通量. 3 个模型中,前两个时段计算结果更接近,2003 年后相差较大. 1990 年前上游水库较少,概算结果总体上应该 可以代表天然情况. 1961-1990 年上游年平均 TP 通量约 22.3(20.3 23.7) 万 $\mathrm{t}$, 其中汛期 (6-10 月) 和非汛 期(11-5 月) 分别为 19.5(17.7 21.0) 万 $\mathrm{t}$ 和 2.8(2.6 3.1) 万 $\mathrm{t}$, 汛期占绝大多数, 非汛期 TP 通量占 $12.6 \%$; 全年、汛期和非汛期 PP 通量分别占相应 TP 的 $93.7 \% 、 95 \%$ 和 $84.5 \%$. 根据模型 2 可以推算得到天然条件下 宜昌断面溶解磷背景通量是 $1.22(0.99 \sim 1.57)$ 万 $\mathrm{t}$. 


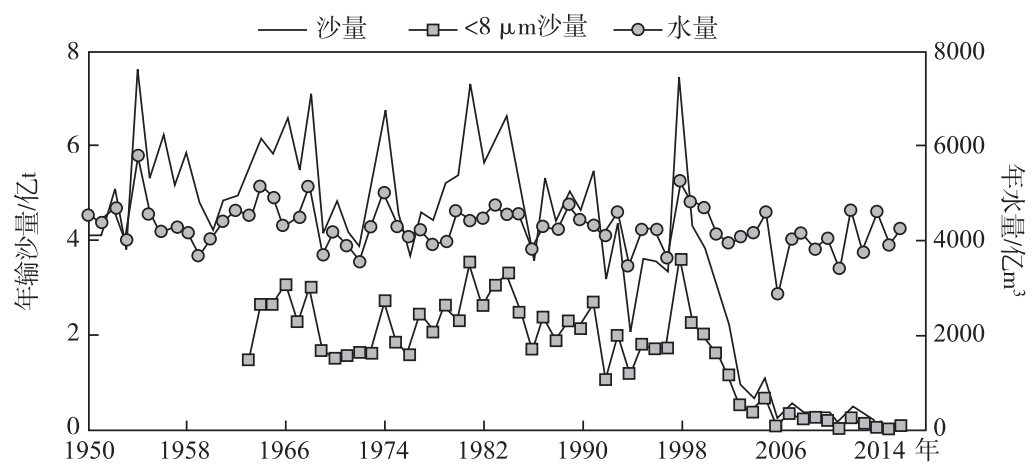

图 3 宜昌断面 1950-2016 年径流量和输沙量(其中 $<8 \mu \mathrm{m}$ 极细沙从 1963 年开始)过程

Fig.3 Long-term variations of runoff and sediment loads with the finest eco-important portion $(<8 \mu \mathrm{m})$ at the Yichang Gauge station (1950-2016)

表 32003 年三峡蓄水前、后各时段长江宜昌断面磷通量概算

Tab.3 Budgets of phosphorus for the upper Yangtze River at Yichang before and after the impoundment of the Three Gorges Reservoir in 2003

\begin{tabular}{|c|c|c|c|c|c|c|c|}
\hline \multirow{2}{*}{ 统计时段 } & \multicolumn{3}{|c|}{$\mathrm{TP} /($ 万 $\mathrm{t} / \mathrm{a}$ ) } & \multicolumn{3}{|c|}{$\mathrm{PP} /($ 万 $\mathrm{t} / \mathrm{a})$} & \multirow{2}{*}{ 方法 } \\
\hline & \multicolumn{6}{|c|}{$1961-1990$ 年 $1991-2002$ 年 $2003-2012$ 年 $1961-1990$ 年 $1991-2002$ 年 $2003-2012$ 年 } & \\
\hline $6-10$ 月 & 19.7 & 15.7 & 3.05 & 18.3 & 14.4 & 2.49 & \multirow[t]{3}{*}{ 模型 1} \\
\hline $11-5$ 月 & 3.1 & 1.5 & 0.18 & 2.5 & 1.2 & 0.11 & \\
\hline 全年 & 22.8 & 17.2 & 3.24 & 20.8 & 15.6 & 2.60 & \\
\hline $6-10$ 月 & 17.7 & 14.5 & 3.60 & 16.9 & 13.7 & 3.01 & \multirow[t]{3}{*}{ 模型 2} \\
\hline $11-5$ 月 & 2.6 & 1.6 & 0.88 & 2.3 & 1.2 & 0.17 & \\
\hline 全年 & 20.3 & 16.1 & 4.48 & 19.2 & 14.9 & 3.18 & \\
\hline $6-10$ 月 & 21.0 & 16.7 & 4.20 & 20.3 & 16.0 & 3.23 & \multirow[t]{3}{*}{ 模型 3} \\
\hline $11-5$ 月 & 2.7 & 1.8 & 1.10 & 2.3 & 1.4 & 0.27 & \\
\hline 全年 & 23.7 & 18.5 & 5.31 & 22.6 & 17.4 & 3.49 & \\
\hline \multicolumn{4}{|c|}{ 时段平均输沙量/(亿 $\mathrm{t} / \mathrm{a})$} & 5.21 & 3.91 & 0.47 & \\
\hline
\end{tabular}

1993-2002 年是三峡蓄水前最近系列, 宜昌总输沙量已经从前期的 5.21 亿 t/a 减少到 3.91 亿 t/a. 但由 于 $8 \mu \mathrm{m}$ 以下的细泥沙仍然保持在 1.9 亿 $\mathrm{t} / \mathrm{a}$ 、减少比例不大 (图 3), 宜昌总磷和 PP 减少都不十分明显, 相应 断面背景溶解磷通量均值增加到 1.25 万 $\mathrm{t} / \mathrm{a}$.

水库淤积改变了长江进人中下游平原河流磷通量格局. 按模型 3 结果 (表 3), 2003-2012 年与 19611990 年比较,宜昌 TP 和 PP 分别减少 77.6\% 和 $84.6 \%$,其中汛期相应减少 $80 \%$ 和 $84.1 \%$, 非汛期减少 $59.2 \%$ 和 $83 \%$. 对比 1990 年前背景值, 流域水库每年拦截颗粒磷 19 万 $\mathrm{t}$ (包括三峡和上游水库作用), 其中 17 万 $\mathrm{t}$ ( $89.3 \%)$ 是汛期通量. 相反, 溶解磷背景值提高比较显著, 模型 2 计算得到的全年通量增加到 1.78 (1.32 2.31) 万 $\mathrm{t}$, 平均值比 1990 年前抬高 $46.2 \%$. 如果考虑到流域排放增加和泥沙在底泥释放等因素, 当前实际的 溶解磷通量应该比上述背景值更大.

尽管下游总磷通量大量减少, 但由于泥沙减少使水中颗粒吸附和封锁磷的能力显著降低, 长江更多的 磷转移到水中. 根据表 3 模型 3 (模型 3 考虑了泥沙级配作用, 推算 DP 结果更合理) 结果表明, 2003-2016 年宜昌全年、非汛期和汛期平均溶解磷通量分别比 1963-1990 年前增加 65\%、108\% 和 38.5\%. 图 4(C 和 D) 中包含了 1963-2016 年长系列背景溶解磷浓度变化情况 (1950-1960 年缺级配资料, 1961-1962 年级配存 在明显问题). 现在非汛期和汛期平均背景 DP 浓度已经从 1990 年前的 0.029 和 $0.027 \mathrm{mg} / \mathrm{L}$ 分别提高到 2009-2016 年的 0.065 和 $0.037 \mathrm{mg} / \mathrm{L}$. 泥沙剧烈减少后, 即使流域磷污染不增加, 长江自然背景磷释放 DP 
也会较大提高, 尤其是非汛期更严重. 产生这一效应的物理本质是泥沙减少导致颗粒吸附磷和河流内部封 磷能力降低, 特别是非汛期, 流量小和水清, 主要来自点源的磷 (不像面源负荷自带泥沙) 进人水体后只能游 离在水中; 同时, 在泥沙面积浓度较大时, 单位泥沙表面积含磷密度更低 (图 2d), 干净泥沙吸附潜力也更大. 泥沙减少使背景 DP 浓度显著抬升, 与当前长江环境监测磷污染增加趋势符合. 除污染增加等原因之外, 泥 沙减少是当前长江中下游溶解磷 (污染指标) 大幅度增加的主要原因.

$\mathrm{BAP} / \mathrm{PP}$ 比例按 $33 \%$ 估算, 上游水库每年拦截 PP 折合 BAP 通量约 6.4 万 $\mathrm{t}$, 这些原来进人长江口及外 海的 BAP 现在都被拦截在水库底泥中. 长江上游水库拦沙彻底改变了长江磷循环路径. 大坝拦截泥沙不但 大量增加磷等污染物在上游河谷累积、显著抬高水域中溶解磷浓度和加大下游淡水水域环境污染压力, 同 时也破坏了河口及周边海域自然磷的供需机制. 这是除泥沙外, 大坝对长江主要物质通量的重大改变.

\section{4 关于总磷监测方法问题与长江磷变化评价}

磷与颗粒物质亲和, 泥沙在静水沉降和 BAP 主要在海水和缺氧环境下释放等特性决定了河流磷、泥沙 和长江磷的生态环境角色与大坝的关系一一水库及调节可大幅度改变河流磷的循环路径和作用规律. 作为 水域生源物质或重要污染物质, 流域磷的状况对河流上下游生态环境和水质都有重要影响. 流域一体化管 理需要完整地监测上下断面和各种状态下河流总磷通量. 然而我国《地表水环境质量标准》( GB $3838-$ $2002)^{[57]}$ 没有完整地监测河流全沙总磷, 规范只要求分析 “澄清样” 总磷, 由于颗粒磷大量被排除, 使相当部 分的磷被漏测.

本文采用三峡蓄水前后库区多断面氮磷实测数据, 同步监测采用泥沙监测规范要求的断面法采样, 同 时分析了全沙浑样、沉淀 $30 \mathrm{mim}$ 澄清样和 $0.45 \mu \mathrm{m}$ 膜过滤后的清样磷含量. 图 4 显示澄清样总磷 (A) 和 DP (B) 与全沙总磷比例. 澄清样总磷恒小于实际全沙总磷, 泥沙浓度越大澄清样总磷和 DP 比例越小. 自然条 件下, 长江上游平均泥沙浓度大于 $1 \mathrm{~kg} / \mathrm{m}^{3}$, 环境监测的澄清样总磷只有全沙总磷一半左右, 溶解磷比例在 $10 \%$ 以下. 水库拦沙, 特别是非洪水期间泥沙浓度减少到 $0.03 \sim 0.06 \mathrm{~kg} / \mathrm{m}^{3}$, 上述比例分别上升到 $80 \%$ 和 $45 \%$ 以上. 泥沙是决定河流磷的关键变量.

图 4 比较了三峡蓄水前后长江宜昌澄清样总磷监测值和全沙总磷差别. 根据图 4(C 和 D) 结果, 三峡蓄 水以来全沙总磷平均浓度在汛期 ( $6-9$ 月) 和非汛期 (10-5 月) 都大量减少, 但澄清样总磷减少程度并不十 分显著, 而且在真正的枯水期 (12-3 月) 澄清样总磷还有增加趋势, 2003-2016 年与 1991-2002 年比较, 枯水期澄清样总磷增加了 $12.4 \%$. 另一方面, 由于水库淤积和泥沙减少使汛期和非汛期背景溶解磷浓度都 大幅上升. 非汛期尤其明显, 2010-2016 年非汛期平均背景溶解磷浓度比 1991-2002 年增加了 1 倍以上. 可见, 即使不考虑流域污染增加, 仅三峡水库淤积的作用也可使其非汛期 (10-5 月)下泄溶解磷浓度从 2003 年前的 $0.035 \mathrm{mg} / \mathrm{L}$ 提高到 2009 年后的 $0.07 \sim 0.08 \mathrm{mg} / \mathrm{L}$. 除图 4 模型 3 的结果外, 根据泥沙浓度变化 (表 3 模型 2) 得到 2003-2012 年非汛期 (11-5 月) 平均 DP 通量也比 1991-2002 年平均增加 $77.5 \%$, 考虑 到 2010-2016 年三峡下泄泥沙进一步减少, 不同模型预报的非汛期背景 DP 浓度增加数量级是相符合的. 而且, 近年来进人河流磷在增加, 实际抬高的 DP 浓度应该更大; 并且本文预测不能反映水库底泥和淤积藻 类释放 DP 作用 (模型主要依据蓄水初期数据), 随着底泥淤积、生物量增加和缺氧蔓延 (图 5), 这种效应还 会增加. 水库淤积使下泄总磷大量减少的同时,也是当前观测到磷污染状况加剧的重要原因.

当前, 河流监测澄清样 TP 方法存在严重问题. 原来, 环境监测主要为当地管理和保护服务, 规范方法作 为水质指标反映环境状况及其相对变化是可以的. 现在, 由于颗粒磷大量漏测, 泥沙对磷的影响机理和实质 不能全面反映出来, 河流上下游、丰枯季节和地区之间污染和通量难以比较, 跨区域通量难以准确考核, 河、 湖与库之间环境评价标准也难于统一. 而且, 监测方法的系统误差和过去对水库泥沙的磷作用机理认识不 完善也导致水库拦磷程度和作用被严重低估, 抬高下游背景溶解磷的事实被掩盖, 甚至导致将监测溶解磷 大幅增加现象归处到流域污染增加, 低估水利工程环境影响和长远危害. 当前, 推进河流保护向流域一体化 管理, 水环境保护向生态系统保护纵深发展, 特别是考虑到人类活动对上下游水域形态、水流状况和各种通 量过程的影响, 一个重要的基础工作是需纠正错误的总磷监测方法, 重新评估水库淤积对磷等环境要素的 影响. 


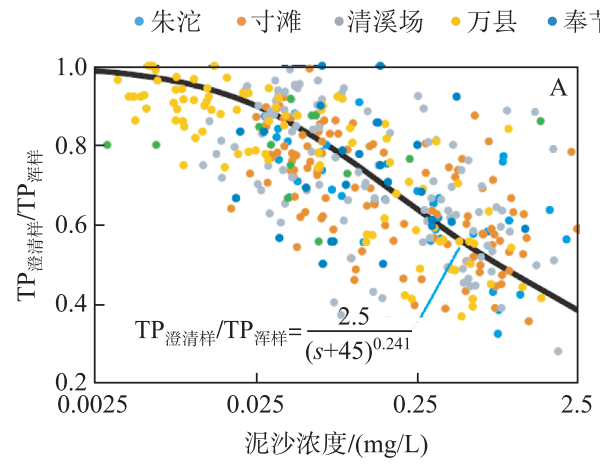

- 北碚・武隆 $12-3$ 月 $-\mathrm{TP}$ - $\mathrm{TP}_{\text {澄清样 }}-\mathrm{DP}$
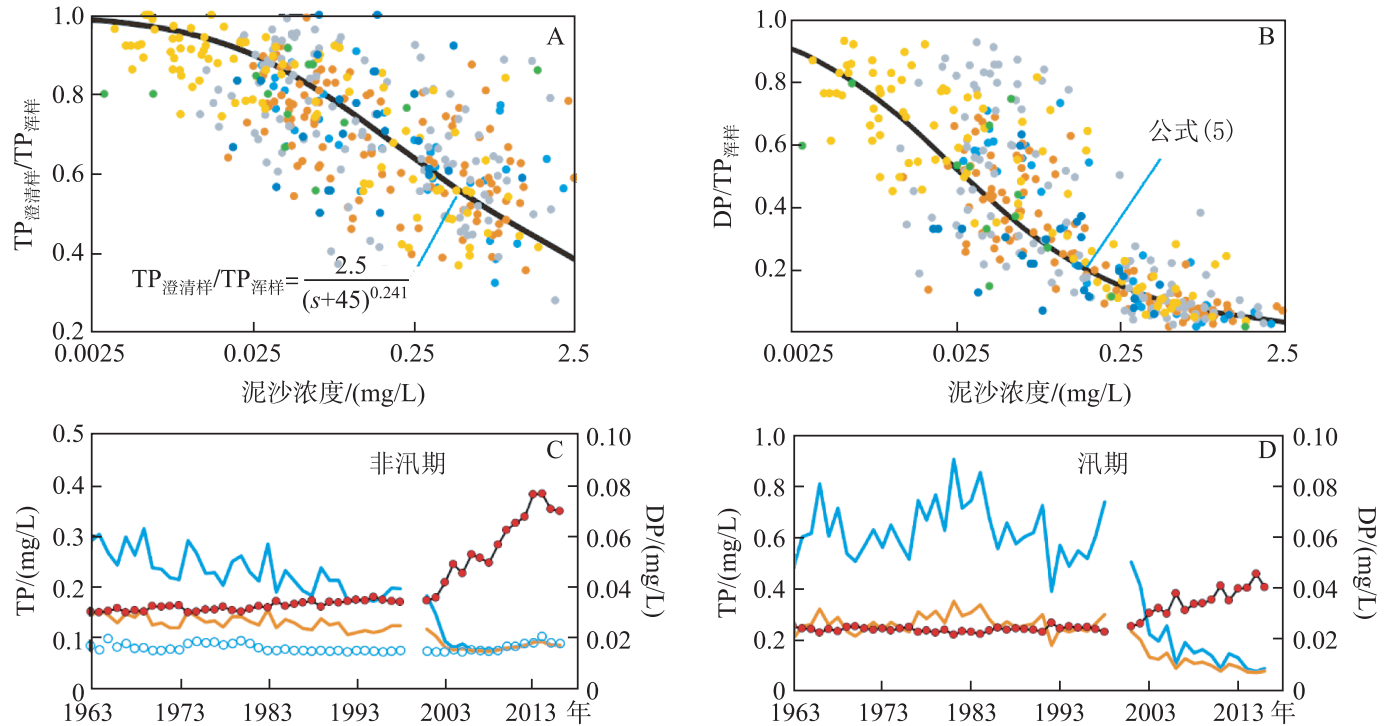

图 4 根据三峡库区多断面采样资料得到长江澄清样总磷 $\left(\mathrm{TP}_{\text {澄清样 }}\right)(\mathrm{A})$ 、

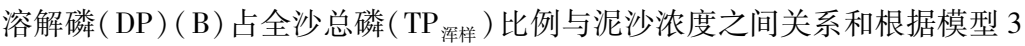

计算 1963 年以来宜昌非汛期 (C) 和汛期 (D) 下泄全沙总磷、澄清样总磷和 DP 浓度变化情况

Fig.4 The specific TP according to government standard (A), DP (B) comparisons with full-sediment

TP against sediment concentration, and simulated variations of different $\mathrm{P}$-fluxes at Yichang gauge station in recent decades ( $\mathrm{C}$ and D for dry and flood seasons, respectively)

\section{5 长江水库淤磷的生态环境效应}

长江上游大量水库拦截沙拦磷, 改变河流磷循环路径和生物有效磷释放机制, 破坏原来河流通过泥沙 封存和调节磷的机制, 增加水库藻密度和促进磷生物沉降. 这些重要河流环境条件改变所产生的作用包括 改变下游磷的通量与节律、改变营养结构、增加水域环境脆弱性和增加水库污染风险等.

\section{1 改变下游河流磷通量与节律}

Blomqvist 等 ${ }^{[54]}$ 实验证明, 海水环境沉淀铁离子使得磷离子大量游离出来, 而一般淡水因铁含量相对较 高而封存磷. 颗粒磷在淡水中比较稳定而进人河口和海洋环境后会大量释放出 来 $^{[55]}$. 长江每年输送约 22 万 $\mathrm{t}$ 磷进人中下游, 其中约 $33 \%$ 是被泥沙封锁而具有潜在环境作用的 BAP (表 2), 其数量大于沿途污染排放 排量. 在自然条件下, 这些磷主要结合在泥沙上集中在汛期随洪水出海. 自然输运特性免除背景磷对淡水环 境的污染, 同时 BAP 在盐水环境中大量释放出来支撑了河口及周边海域初级生产力. 这是磷的自然循环及 其生物有效磷释放规律和生态环境优势.

水库拦截泥沙使这样的机制发生了根本变化. 一方面, 长江口生物系统本来受磷限制, 水库大量拦截又 使其失去了原有的 BAP 补充; 河口及周边海域环境容量巨大, 原来大量释放的 BAP 是支撑这里繁荣生境和 初级生产力的关键营养; BAP 资源减少后, 浮游生物系统可以消费的碳氮也会降低. 另一方面, 水库大量颗 粒磷滞留在河流上游水库底泥中, 在高有机质、缺氧和富营养环境下, BAP 也会大量释放 ${ }^{[56-60]}$. 水库拦截使 原来汛期大量随泥沙人海的颗粒磷停留在上游水库中并持续释放 BAP, 影响自身和下游淡水系统. 三峡水 库近坝段 100 余千米范围在 2014 年已经监测到溶解氧低于 $3 \mathrm{mg} / \mathrm{L}$ 、非汛期水温严重超高 (图 5). 三峡库区 营养程度高、藻类发育和支流连年水华, 同时这些因素都更会促进 BAP 在适当时机暴发出来, 造成大范围 水华. 
水库改变了长江磷的循环路径、释放机制和作用,使河口及周边海域的资源变成了河流上游淡水生态 系统的污染. 这是一个严重遗憾, 其后果是否对当前鱼类大量减少、舟山渔场消亡和长江口周边海域水质恶 化等有关, 值得认真研究.

\section{2 改变中下游营养结构和增加环境脆弱性}

大量研究显示自然水域正常生物代谢营养结构指标 (氮磷比, N/P) 一般在 $15 \sim 16^{[63-64]}$ 或以此为平均值 的一定范围内 ${ }^{[64]}$. 由于流域污染增加和大量使用化肥, 长江口 N/P 在 2000 年前已长期超正常水平, N/P = $350 \sim 450^{[65]}$, 磷是长江口及其周边海域浮游生物限制性营养 ${ }^{[8-11,13]}$. 同时, 伴随三峡等水库和中下游变清变 暖, 水体失去对污染的缓冲机制、溶解磷浓度增加、自净能力和污染承受能力降低等也增加了长江水域的环 境脆弱性.

长江上游水库每年拦颗粒磷超过 20 万 $\mathrm{t}$ (潜在 BAP 比例按 $25 \%$ 33\% 计算) 使河口外潜在 BAP 资源减 少 6.0 万 7.0 万 t. 如此大体量限制营养减少后, 河口及周边海域营养状况与环境条件必然发生改变, 影响初 级生产力和浮游生物, 藻类也会发生选择性变异. 多瑙河上游建坝改变河流营养结构而改变下游海域藻类 的同时使甲藻、颗石藻和寄生有害藻大量增加 ${ }^{[66]}$, 阿斯旺高坝拦沙拦磷严重影响尼罗河地中海河口初级生 产力与鱼产量 ${ }^{[6]}$ 都是经典例子.

限制营养减少还会相对抬高下游碳氮等污染水平. 根据磷限制条件, 按与正常水域浮游生物固定营养 盐比例 $\mathrm{C}: \mathrm{N}: \mathrm{P}=105: 16: 1$ 的偏差可估计水库拦磷对河口固定碳氮能力的影响 ${ }^{[9]}$. 概算显示, 上述 BAP 减少 可使河口及周边浮游生物固碳和固氮量分别减少 194 万和 34 万 $\mathrm{t}^{[18]}$. 这种数量级概算虽然准确度低, 但其 重要性在于其尺度已经与长江主要碳 (颗粒有机碳) 氮 (溶解无机氮) 通量 ${ }^{[9]}$ 数量级相同, 其危害是显然的. 因此, 碳氮水平相对抬高也进一步促进业已严重碳氮污染的河口水质变差. 近 10 余年来, 河口及周边海域 长期高比例维持在劣 IV 类 (杭州湾 $100 \%$ ), 情况非常严峻. 这是河口污染控制和环境治理必须首先研究和高 度重视的大问题.

泥沙是水中重要磷库, 发挥着污染缓冲和营养调节等重要作用 ${ }^{[19,68-70]}$. 一方面, 泥沙颗粒吸附可有效降 低高磷污染期间水体溶解磷浓度、减小污染时空尺度和程度. 另一方面, 又可通过解吸补充低磷期间浮游生 物磷需求, 维持水体正常营养水平. 同时, 河流汛期大量泥沙集中排磷出海, 年内冲淤使不同季节污染和营 养得到有效平衡和有利配置, 使淡水系统磷污染降低、生态作用提高、封存和汛期集中排磷并支撑近海生境 和环境. 这是自然河流自净能力的重要体现, 是环境容量. 长江变成了“清水” 河流使这些作用消失. 在上游 大量水库长期拦沙条件下, 中下游自然的沙质河床也将逐步变成硬质河床, 水体抵抗污染能力与维持必要 初级生产力的能力必然受到影响. 而且, 泥沙减少使水体透光度增加、水库和缓流水域藻类增加. 实测资料 显示, 三峡库区非汛期水体透光深度比长江自然水体透光深度增加 $8 \sim 10$ 倍 (从 $0.3 \sim 0.4 \mathrm{~m}$ 增加到 $2 \sim 3 \mathrm{~m}$ )、 藻密度提高 1 个数量级 $\left(1999-2002\right.$ 年巴东平均藻密度为 $2 \times 10^{4} \sim 3 \times 10^{4}$ cells $/ \mathrm{L}, 2003-2008$ 年 $20 \times 10^{4} \sim 30 \times$ $\left.10^{4} \mathrm{cells} / \mathrm{L}\right)^{[17]}$. 浮游生物增加加快磷循环和生物代谢也会大量增加耗氧. 特别是三峡水库秋末至春初水温 已经显著抬高, 饱和溶解氧严重降低 (图 5), 在相同条件下水体承受污染的能力也会受到影响. 从水库拦截 $\mathrm{BAP}$ 数量和水温变化对饱和溶解氧影响尺度看, 这些影响是严重的. 特别是水库大幅抬高背景 DP 浓度. 前 面模型预测是在不考虑流域污染增加情况下枯水期水库下泄 DP 浓度提高 1 倍, 这是当前流域污染控制关 注的重要问题. 其根本原因是泥沙对磷的缓冲作用丧失使河流不能稳定发挥和调节磷的作用. 在环境容量 更低的非汛期清水情况下, 磷主要以 DP 方式存在并直接进人环境循环, 增加下游污染、提高藻密度和环境 脆弱性.

\section{3 增加了三峡等水库污染风险}

承接来自上游百万平方公里和 1.6 亿人口污染排放, 三峡是全球大河上罕见的大型干流人工水体, 水质 安全关系到广大地区, 必须高度重视任何可能的环境风险.

水库改变长江磷循环路径后, 大量潜在污染积累到上游水库. 实测显示泥沙和污染沉降使三峡水库每 年沉积碳氮磷等数量远高于一般湖泊, 概算显示上游水库拦截到底泥的 BAP 数量超过人类活动排放. 由于 泥沙锁磷作用降低, 水库拦磷和降低下游磷通量的同时下泄溶解磷浓度又大幅提高 (图 4C 和 D). 沉积磷、 有机物和其他营养物质在水库底泥缺氧环境和庆氧微生物作用下迟早会释放出来. 
目前三峡水库冬季水温 $\left(2009-2014\right.$ 年) 比天然升高 $4^{\circ} \mathrm{C}$ 以上, 水温高出气温 $10 \sim 13^{\circ} \mathrm{C}$ 、近坝段已观测 到缺氧 $(\mathrm{DO}<3 \mathrm{mg} / \mathrm{L})$ ( 图 5). 水温升高降低饱和溶解氧 $\left(-0.3 \mathrm{mg} /\left(\mathrm{L} \cdot{ }^{\circ} \mathrm{C}\right)\right.$ ), 三峡水库超温影响饱和溶解氧 程度已与宜昌年平均 $\mathrm{COD}_{\mathrm{Cr}}$ 和 $\mathrm{BOD}_{5}$ 同量级 $\left(\mathrm{COD}_{\mathrm{Cr}}=5 \mathrm{mg} / \mathrm{L}, \mathrm{BOD}_{5}=1.6 \mathrm{mg} / \mathrm{L}\right)$. 库区 $\mathrm{TP}$ 和 $\mathrm{TN}$ 浓度实际上 已经与太湖不相上下, 而且藻密度高; 一级支流库区 I III类水质比例低、支流库区连年发生水华, 只是水库 仍按河流标准评价, 干流水质仍维持在 II III类. 特别值得强调的是, 三峡水库没有温度分层现象, 底部水温 更高于同类其他水库. 上下层之间热和物质交换更有利于刺激底泥中磷和其他有机质分解并快速进人表层 促藻类生长.

更进一步, 在三峡上游干热河谷地区大量大型水库(乌东德、白鹤滩、溪洛渡和向家坝等) 已经和即将蓄 水, 还将进一步增加吸热、抬高冬天水温并大量转移到相对阴冷的三峡库区抬高水温和缺氧程度. 初步资料 显示, 2013 年向家坝、溪洛渡和亭子口前后蓄水后, 朱沱、寸滩三峡人库和宜昌冬天水温 (2014-2016 年平 均) 又分别抬高了 $4 、 2$ 和 $1^{\circ} \mathrm{C}$. 堆积在上游库底的 BAP 释放出来和泥沙封磷作用降低也会抬高三峡人库溶 解磷浓度. 这些环境压力对三峡水库水质安全都是严重的挑战.

北欧波罗的海水域面积 41.5 万 $\mathrm{km}^{2}$,流域人口 8500 万. 东欧 50 年沿岸国家分别排放 2000 万 $\mathrm{t}$ 氮和 200 万 $\mathrm{t}$ 磷, 其中磷主要沉积在湖底, 现在尽管绝大部分污染负荷已经消除但仍然每年出现 6 万 $\mathrm{km}^{2}$ 蓝藻水华和 严重缺氧 ${ }^{[17]}$. 三峡水库最大面积 $1080 \mathrm{~km}^{2}$, 长江上游所有水库总面积不足前者 $1 \%$, 而三峡上游人口远大于 前者. 根据概算, 三峡及上游水库 30 年可沉降的 BAP 将超过波罗的海 50 年沉积的磷. 这种由内源造就的严 重富营养化水体和环境危害当今十分普遍. 我们必须对位于长江干流最下游的三峡水库可能发生大面积水 华和缺氧风险高度重视.

\section{6 长江干流磷修复措施}

河流变清是长江近期发生的重大改变, 上游水库拦沙同时改变了河流磷的循环路径和 BAP 释放机制. 作者认为这是当前长江生态环境的主要问题之一, 长江干流生态环境修复的重点之一应该是河流物质通量 修复 ${ }^{[56]}$, 建议在上游大型水库挖泥并直接用以修复下游非汛期水体磷和浑浊度、减少水库淤积的同时渐进 消除磷等污染物质在河流内部累积.

根据三峡水库泥沙和磷分选淤积的模型计算 ${ }^{[18]}$, 在水库淤积过程中, 含磷量较高的泥沙都主要集中淤 积在靠近坝前的深水库段, 而泥沙、磷和透光度改变影响比较严重的时间是非汛期. 因此, 建议将非汛期 (10一翌年 5 月)下游水体的透光度和颗粒磷通量恢复到以建库前 11 一翌年 5 月平均水平并以逐月天然值为 上限. 以 1961－1990 和 1991－2002 年两个时段平均情况作为修复目标计算 (表 4), 恢复浑浊度需要的挖泥 量分别需要 1460 万或 1140 万 $\mathrm{t} / \mathrm{a}$, 恢复磷通量需要挖泥 2710 万或 1430 万 $\mathrm{t} / \mathrm{a}$. 综合考虑恢复自然浑浊度和 磷通量需要挖泥 2780 万或 1470 万 $\mathrm{t} / \mathrm{a}$.

表 4 根据 2008-2016 年三峡下泄平均情况, 分别按透光度和颗粒磷目标恢复到 1961-1990 或 1991－2002 年平均情况计算,需要在三峡近坝段的年挖泥量 (万 $\mathrm{t} / \mathrm{a}$ )

Tab.4 Estimated sediment needed to dredge from the Three Gorges Reservoir each year in restoring the dry seasons downstream light transparence and particle phosphorus to the 1961-1990 and 1991-2002 levels

\begin{tabular}{ccccccccccc}
\hline 时段 & 目标 & 1月 & 2月 & 3 月 & 4月 & 5月 & 10月 & 11月 & 12 月 & 总量 \\
\hline \multirow{2}{*}{$1991-2002$ 年 } & 透光度 & 22 & 18 & 22 & 182 & 338 & 278 & 237 & 50 & 1140 \\
& 颗粒磷 & 23 & 15 & 22 & 146 & 388 & 385 & 391 & 64 & 1430 \\
& 综合 & 23 & 18 & 22 & 182 & 388 & 385 & 391 & 64 & 1470 \\
$1961-1990$ 年 & 透光度 & 78 & 45 & 106 & 217 & 338 & 278 & 237 & 165 & 1460 \\
& 颗粒磷 & 58 & 32 & 70 & 350 & 680 & 677 & 673 & 178 & 2710 \\
& 综合 & 78 & 45 & 106 & 350 & 680 & 677 & 673 & 178 & 2780 \\
\hline
\end{tabular}

按公益挖泥定位, 假设挖泥单价 8 元/ $\mathrm{t}$ 匡算 (疏浚直接抛泥, 不运输、不分选、不清洗和没有税赋等,还 可采用电站供电, 只考虑人员费用), 上述两种修复目标挖泥需要的费用分别是 2.2 亿和 1.1 亿元/a. 当然对 

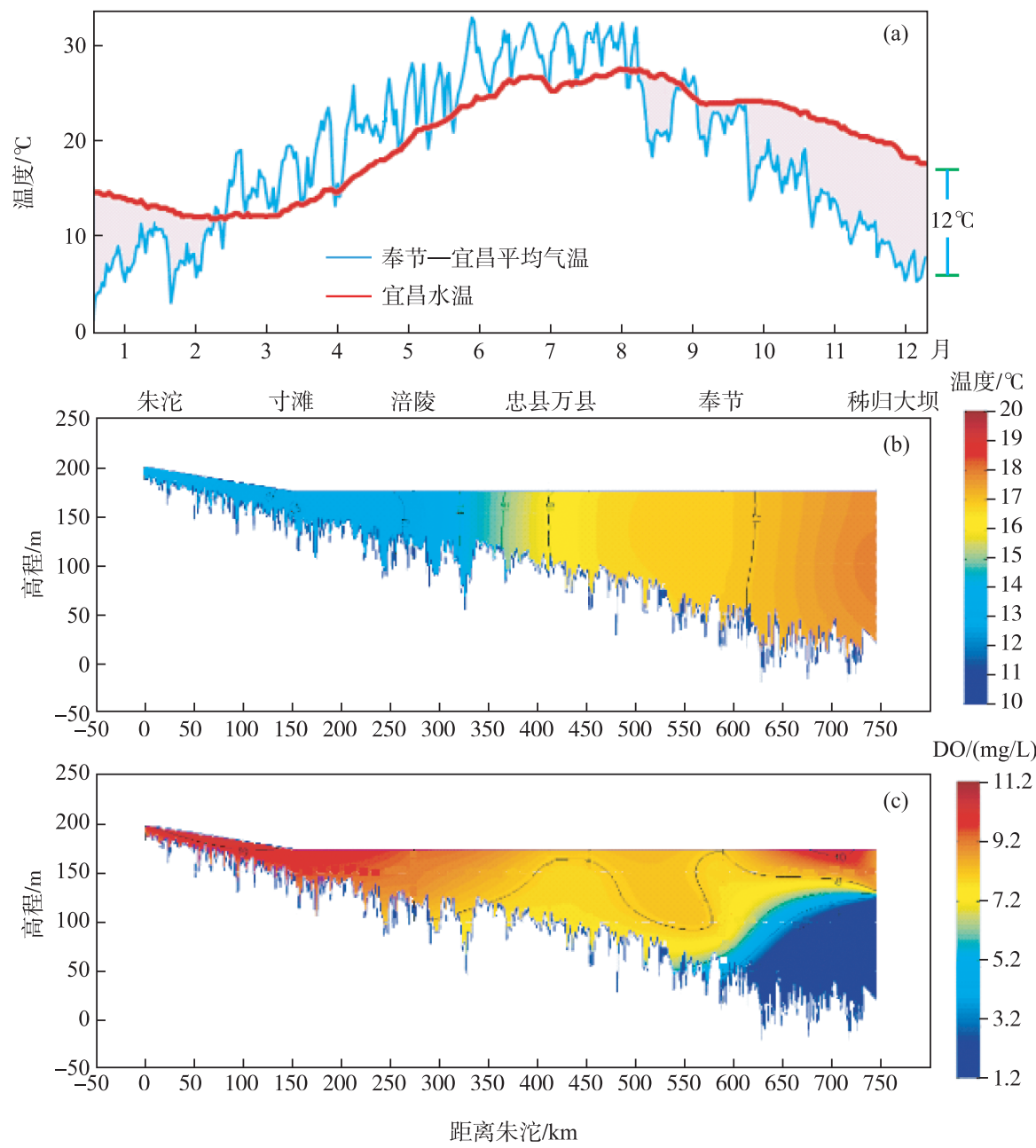

图 5 奉节至宜昌 2013 年气温与宜昌水温对比 (a) 以及 2014 年 12 月三峡库区实测水温 (b) 和溶解氧浓度 (c) 沿程分布

Fig.5 Comparison of air and pool temperature in reach from Fengjie to Yichang in 2013(a), measured temperature (b) and DO concentration(c) distribution in Dec. 2014 in the Three Gorges Reservoir

于梯级水库,相应上游水库也需要挖泥, 浑水进人下游水库对稳定库区水质是有益的. 挖泥的费用只是这些 电厂发电收人 (上网电价) 很小部分, 完全可以也应该由相应电厂承担. 从现在起循序渐进消除上游内源污 染, 可以免除今后长江的内源污染后患. 这种修复完全按照自然通量确定, 而且完全能在线监控, 挖泥增加 的磷物质等对下游河流应该不会造成污染. 三峡非汛期恢复自然泥沙和磷通量可以提高下游水体环境容 量, 最大限度发挥河流自然自净能力, 对改善下游水域生境、补充河口及周边海域需要限制营养, 改善生态 和长三角周围海水水质也应该有所帮助.

这种大规模通量修复没有先例, 其具体做法、效果和存在问题都需要实践检验. 因此, 建议先在三峡近 坝段开展示范挖泥并从水库到河口展开全面监测和研究.

\section{7 结论和展望}

根据大量研究成果综合分析了长江磷与泥沙的关系、磷的自然循环规律和水库改变磷循环的作用, 得 
到如下基本认识:

1) 长江磷以颗粒态为主, 与泥沙关系密切, 受泥沙影响显著; 河流输送颗粒磷的潜在生物有效磷比例和 数量大;水库大量淤积泥沙也大量拦截磷而对氮等其他营养作用较小.

2) 上游大量梯级水库彻底改变了长江中下游泥沙状况,使原本浑浊和冲积型的中下游变成“清水”河 流, 水库也同时拦截超过 $75 \%$ 总磷和大约 6 万 10 万 $\mathrm{t}$ 潜在生物有效磷, 其潜在环境作用超过当前人类活动 注人磷的数量.

3) 大坝彻底改变磷循环路径、释放机制和作用. 长江颗粒态磷从原来河口及周边海域的生态资源变成 了上游水库积累的潜在污染; 相应加剧水域营养或污染物结构退化, 提高下游溶解磷背景值, 推高河口和周 边海域碳、氮污染的相对程度; 增加中下游环境脆弱性和降低环境容量. 水库积磷在底泥缺氧中或逐步成为 河流内部污染源、下游河湖库 (特别是干流最下游的重要水库) 水质安全的威胁. 水库改变磷循环路径和释 放规律是当前长江生态环境面临的主要问题之一.

4) 我国河流地表水环境监测规范中磷测量方法存在严重问题. 澄清样磷方法不能分析全沙, 磷大量漏 测. 上下游、河湖库和汛枯之间监测结果难统一,水质标准不一样. 因此严重低估水库对河流磷的作用,掩盖 水库抬高背景溶解磷现象, 使河流上游潜在内源污染不断坐大的危险得不到重视, 也不利于污染源解析、跨 界断面考核和流域一体化管理. 建议尽快修正.

5) 建议在上游大型水库近坝段非汛期持续挖泥修复下游河流物质通量、消除或控制潜在污染内源的积 累. 考虑到当前长江生态环境形势, 水、生态和环境安全和长远计, 建议首先在三峡水库进行示范和试验.

在流域开发带来巨大利益的同时,通过彻底改变河流泥沙和磷等物质通量等对河流基本环境条件构成 实质性改变. 当前必须扭转过去以资源利用为主和现实利益最大的开发管理方式, 高度重视环境安全和长 远风险, 走低影响发展道路. “共抓大保护” 需要转变流域资源利用方式和修复长江, 需要理清河流生态环境 面临的主要问题和抓住重点. 同时,我国很多多沙河流被大坝改变了下游平原河流基本环境条件,而我们对 其作用、危害和长期效应认识很不充分, 考虑到大河下游繁荣地区水和环境安全极其重要, 建议高度重视和 加强对大坝影响河流通量的研究.

\section{8 参考文献}

[ 1 ] Zhou JJ, Zhang M. On the forefront ecological and environmental problems of current Yangtze River and restoration priorities. Environmental Protection, 2017, 45(617) : 17-24. [周建军, 张曼. 当前长江生态环境主要问题与修复重点. 环 境保护, 2017, 45(617): 17-24.]

[ 2 ] Qian N, Zhang R, Zhou ZD eds. Fluvial processes. Beijing: Science Press, 1987. [ 钱宁, 张仁, 周志德. 河床演变学. 北京: 科学出版社, 1987 .

[ 3 ] Han QW, He MM, Xu JL eds. Supplementary computation of deposition of the 175 scheme TGP. Publication on research of the key problems in sediment and navigation of the Three Gorges Project. Wuhan: Wuhan Polytech Univ Press, 1992: 539-550. [ 韩其为, 何明民, 徐俭立. 三峡水库 175 方案补充计算结果. 长江三峡工程泥沙与航运关键技术研 究——专题研究报告集. 武汉: 武汉工业大学出版社, 1992: 539-550.]

[ 4 ] Changjiang Water Resource Commission ed. Studies on sediment problems of the Three Gorges Project. Wuhan: Hubei Science and Techology Press, 1997. [ 长江水利委员会. 三峡工程泥沙研究. 武汉: 湖北科学技术出版社, 1997.]

[ 5 ] Conley DJ, Paerl HW, Howarth RW et al. Controlling eutrophication: Nitrogen and phosphorus. Science, 2009, 323: 1014-1015.

[ 6 ] Nixon SW. Replacing the Nile: Are anthropogenic nutrients providing the fertility once brought to the Mediterranean by a great river? Royal Swedish Academy of Sciences, 2003, 32(1) : 30-39.

[ 7 ] Pan G, Krom MD, Herut B et al. Adsorption-desorption of phosphate on Airborne dust and riverborme particulates in East Mediterranean seawater. Environ Sci Technol, 2002, 36: 3519-3524.

[ 8 ] Edmond JM, Spivack A, Grant BC et al. Chemical dynamics of the Changjiang estuary. Cont Shelf Res, 1985, 4(1/2): $17-36$.

[ 9 ] Zhang J, Zhang ZF, Liu SM et al. Human impacts on the large world rivers: would the Changiiang (Yangtze River) be an illustration? Global Biogeochem Cycl, 1999, 3(4) : 1099-1105. 
[10] Liu SM, Zhang J, Chen HT et al. Nutrients in the Changjiang and its tributaries. Biogeochemistry, 2003, 62: 1-18.

[11] Shen ZL. Phosphorus and silicate fluxes in the Yangtze River. Acta Geographica Sinica, 2006, 61(7): 741-751. [ 沈志 良. 长江磷和硅的输送通量. 地理学报, 2006, 61(7): 741-751.]

[12] Zeng H, Song L, Yu ZG et al. Post-impoundment biomass and composition of phytoplankton in the Yangtze River. Int Rev Hydrobiol, 2007, 92(3): 267-280.

[13] Duan SW, Liang T, Zhang S et al. Seasonal changes in nitrogen and phosphorus transport in the lower Changjiang River before the construction of the Three Gorges Dam. Estuarine, Coastal and Shelf Science, 2008, 79: 239-250.

[14] Shen ZL, Liu Q. Nutrients in theChangjiang River. Environ Monit Assess, 2009, 153: 27-44.

[15] Wei JF, Chen HT, Liu PX et al. Phosphorus forms in suspended particulate matter of the Yangtze River. Advances in Water Science, 2010, 21 (1) : 107-112. [魏俊风, 陈洪涛, 刘鹏霞等. 长江悬浮颗粒物中磷的赋存形态. 水科学进展, 2010, 21 (1): 107-112.]

[16] Müller B, Berg M, Pernet-Coudrier P et al. The geochemistry of the Yangtze River: Seasonality of concentrations and temporal trends of chemical loads. Global Biogeochem Cycles, 2012, 26: GB2028. DOI:10.1029/2011GB004273.

[17] Zhou J, Zhang M, Lu P. The effect of dams on phosphorus in the middle and lower Yangtze river. Water Resources Research, 2013, 49(6): 3659-3669.

[18] Zhou J, Zhang M, Lin B et al. Lowland fluvial phosphorus altered by dams. Water Resources Research, 2015, 51 (4): 2211-2226.

[19] Müller B, Finger D, Sturm M et al. Present and past bio-available phosphorus budget in the ultra-oligotrophic Lake Brienz. Aquat Sci, 2007, 69: 227-239.

[20] Zhou J, Lin B. One-dimensional mathematical model for suspended sediment by lateral integration. J Hydraulic Eng, 1998, 124: 712-717.

[21] Zhou J, Lin B. Verification of mathematical model for sediment transport by unsteady flow in the lower Yellow River. Int J Sediment Res, 2004, 19: 278-291.

[22] Smil V. Phosphorus in the environment: Natural flows and human interferences. Annual Rev Energy Environ, 2000,25 : 53-88.

[23] Wang R, Balkanski Y, Boucher O et al. Significant contribution of combustion-related emissions to the atmospheric phosphorus budget. Nat Geosci, 2015, 8: 48-54.

[24] Xu Kaiqin, Hayashi Seiji, Murakami Shogo et al. Characteristics of water quality in the Changjiang River: Observations conducted in 1998 and 1999. Acta Geographica Sinica, 2004, 59(1): 118-124. [徐开钦, 林诚二, 牧秀明等. 长江干 流主要营养盐含量的变化特征—-1998-1999 年日中合作调研结果分析. 地理学报, 2004, 59(1):118-124.]

[25] Müller B, M Berg, Yao ZP et al. How polluted is the Yangtze river? Water quality downstream from the Three Gorges Dam. Science of the Total Environment, 2008, 402: 232-247.

[26] Meybeck M. Carbon, nitrogen, and phosphorus transport by world rivers. Am J Sci, 1982, 282 : 401-450.

[27] Russell MA, Walling DE, Webb BW et al. The composition of nutrient fluxes from contrasting UK river basins. Hydrological Process, 1998, 12: 1461-1482.

[28] Milliman JD, Meade RH. World-wide delivery of river sediment to the oceans. Journal of Geology, 1983, 91(1) : 1-21.

[29] Meybeck M, Ragu A. GEMS-GLORI world river discharge database. Laboratoire de Géologie Appliquée, Université Pierre et Marie Curie, Paris, France, 2012. DOI: 10.1594/PANGAEA.804574.

[30] Forsberg BR, Devol AH, Richey JE et al. Factors controlling nutrient concentrations in Amazon floodplain lakes. Limnology and Oceanography, 1988, 33(1): 41-56.

[31] Ramesh R, Purvaja GR, Subramanian V. Carbon and phosphorus transport by the major Indian rivers. Journal of Biogeography, 1995, 22(2/3): 409-415.

[32] Duan SW, Zhang S. The variations of nitrogen and phosphorus concentrations in the monitoring stations of three major rivers in China. Science Geographica Sinica, 1999, 19(5): 411-416. [段水旺, 章申. 中国主要河流控制站氮、磷含量变化 规律初探. 地理科学, 1999, 19(5):411-416.]

[33] Saunders III JF, Lewis JR WM. Transport of phosphorus, nitrogen, and carbon by Apure River, Veneuela. Biogeochemistry, 1988, 5: 323-342.

[34] USGS. Annual nutrient flux and concurrent stream flow to the Gulf of Mexico for the period of 1996-2005. http: // toxics. 
usgs.gov/pubs/of-2007-1080/delivery/gulf_annual_loads.html.

[35] Sutula M, Bianchi TS, Mckee BA. Effect of seasonal sediment storage in the lower Mississippi River on the flux of reactive particulate phosphorus to the Gulf of Mexico. Limnology and Oceanography, 2004, 49(6) : 2223-2235.

[36] Goolsby DA, Battaglin WA, Lawrence GB et al. Flux and sources of nutrients in the Mississippi-Atchafalaya river basin, Topic 3 Report, National Science and Technology Council Committee on Environment and Natural Resources Hypoxia Work Group, 1999.

[37] Meybeck M. Fluvial export in biogeochemistry of inland waters. In: Ligens ed. Elsevier: Academic Press, 2009: 118-129.

[38] Teodoru C, Wehrli B. Retention of sediments and nutrients in the Iron Gate I Reservoir on the Danube River. Biogeochemistry, 2005, 76: 539-565.

[39] International Research and Training Center on Erosion and Sedimentation ( IRTCES). River sediment bulletin of China 2000, Beijing, http:// www.irtces.org/database.asp.

[40] Delmas M, Cerdan O, Cheviron B et al. Sediment export from French rivers to the sea. Earth Surf Process Landforms, 2010, 37 : 754-762.

[41] Ignatieva NV. Nutrient exchange across the sediment-water interface in the eastern Gulf of Finland. Boreal Environment Research, 1999, 4: 295-305.

[42] Horowitz AJ, Elrick KA, Smith JJ. Annual suspended sediment and trace element fluxes in the Mississippi, Columbia, Colorado and Rio Grande drainage basin. Hydrological Processes, 2001, 15: 1169-1207.

[43] Stanford JA, Ward JV. Limnology of Lake Powell and the chemistry of the Colorado River. Colorado River Ecology and Dam Management: Proceedings of a Symposium May 24-25, 1990, Santa Fe, New Mexico.

[44] Guo LD, Zhang JZ, Gueguen C. Speciation and fluxes of nutrients ( N, P, Si) from the upper Yukon River. Global Biogeochemical, 2004, 18: GB1038.

[45] Barlow JP, Glase MS. Partitioning of phosphorus between particles and water in a river outflow. Hydrobiologia, 1982,91 : 253-260.

[46] Cai YH, Guo LD, Douglas TA et al. Seasonal variations in nutrient concentrations and speciation in Chena River, Alaska. Journal of Geophysical Res, 2008, 113: G03035.

[47] Nilsson N, Reidy CA, Dynesius M et al. Fragmentation and flow regulation of the world's large river systems. Science, 2005, 308: 405-408.

[48] Garnier J, Nemery J, Billen G et al. Nutrient dynamics and control of eutrophication in the Marne River system: modelling the role of exchangeable phosphorus. Journal of Hydrology, 2005, 304: 397-412.

[49] Duan SW, Zhang S, Chen XB et al. Concentration of nitrogen and phosphorus and nutrient transport to estuary of the Yangtze River. Environmental Science, 2000, 21(1) : 53-56. [段水旺, 章申, 陈喜保等. 长江下游氮、磷含量变化及其输 送量的估计. 环境科学, 2000, 21 (1):53-56.]

[50] Howarth R, Jensen H, Marino R et al. Transport to and processing of P in near-shore and oceanic waters. SCOPE, 1995, 54: 323-345.

[51] Howarth RW, Billen G, Swaney D et al. Regional nitrogen budgets and riverine N \& P fluxes for the drainages to the North Atlantic Ocean: Natural and human influences. Biogeochemistry, 1996, 35(1) : 75-139.

[52] Chongqing Academy of Environmental Sciences. Total phosphorus prevention and control countermeasures in Yangtze river watershed of Chongqing section, Research Report, 2017. [重庆市环境科学研究院. 重庆长江流域总磷防控对策研究. 研究报告, 2017.]

[53] Hubei Academy of Environmental Sciences. Total phosphorus prevention and control countermeasures in Yangtze river watershed of Hubei section, Research Report, 2017. [湖北环境科学研究院. 湖北省长江流域总磷防控对策研究. 研究 报告, 2017.]

[54] Blomqvist S, Gunnars A, Elmgren R. Why the limiting nutrient differs between temperate coastal seas and freshwater lakes: A matter of salt. Limnology and Oceanography, 2004, 49(6): 2236-2241.

[55] Zhang JZ, Huang XL. Effect of temperature and salinity on phosphate sorption on marine sediments. Environ Sci Technol, 2011, 45: 6831-6837.

[56] Zhou JJ, Zhang M. On the restoration strategies of alluvial rivers downstream of dams. Journal of Yangtze River Scientific Research Institute, 2014, 31(6) : 113-122. [ 周建军, 张曼. 大坝下游冲积河流修复与保护对策研究. 长江科学院院 
报, 2014, 31(6): 113-122.]

[57] Ministry of Enrivonmental protection of the People's Republic of China. Environmental quality standards for surface water. GB 2828-2002. [环境保护部. 地表水环境质量标准, GB 3838-2002.]

[58] Sonzogni WC, Chapra SC, Armstrong DE et al. Bioavailability of phosphorus inputs to lakes. Journal of Environmental Quality, 1982, 11(4) : 555-563.

[59] Boström B, Andersen JM, Fleischer S. Exchange of phosphorus across the sediment-water interface. Hydrobiologia, 1988, 170: $229-244$

[60] Nünberg GK. The prediction of internal phosphorus load in lakes with anoxic hypolimnia. Limnology and Oceanography, 1984, 29: 111-129.

[61] Hupfer M, Lewandowski J. Oxygen controls the phosphorus release from lake sediments-A long-lasting paradigm in limnology. International Review of Hydrobiology, 2008, (4/5) : 415-432.

[62] Conley DJ. Save the Baltic Sea. Nature, 2012, 486: 463-464.

[63] Redfield AC. The biological control of chemical factors in the environment. American Scientist, 1958, 46: 205-222.

[64] Tyrrell T. The relative influenced of nitrogen and phosphorus on oceanic primary production. Nature, 2005, 400: 525-531.

[65] Klausmeier CA, Litchman E, Daufresne T et al. Optimal nitrogen-to-phosphorus stoichiometry of phytoplankton. Nature, 2004, 429: 171-174.

[66] Yu LH, Li DJ, Fang T et al. Distribution of DSi, DIN and changes of Si: $\mathrm{N}$ ratio on the summer in Changjiang estuary before and after storage of Three Gorges Reservoir. Acta Ecologica Sinica, 2006, 26(9) : 2817-2826. [余立华, 李道季, 方 涛等. 三峡水库蓄水前后长江口水域夏季硅酸盐, 溶解无机氮分布及硅氮比值的变化. 生态学报, 2006, 26(9): 2817-2826. ]

[67] Humborg C, Ittekkot V, Cociasu A et al. Effect of Danube river dams on Black Sea biogeochemistry and ecosystem structure. Nature, 1997, 386(27) : 385-388.

[68] Zhang J, Fischer C, Ortner P. Potential availability of sedimentary phosphorus to sediment resuspension in Florida Bay. Global Biogeochem Cycles, 2004, 18: GB4008.

[69] Wildman RA, Hering JG. Potential for release of sediment phosphorus to Lake Powell (Utah and Arizona) due to sediment resuspension during low water level. Lake Reservoir Manage, 2011, 27 : 365-375.

[70] Zhang J, Huang X. Relative importance of solid-phase phosphorus and iron on the sorption behavior of sediments. Environ Sci Technol, 2007, 41(8): 2789-2795. 